\title{
Pharmacological recommendations for the symptomatic treatment of dementia: the Canadian Consensus Conference on the Diagnosis and Treatment of Dementia 2012
}

\author{
Nathan Herrmann ${ }^{* 1,2}$, Krista L Lanctôt', and David B Hogan³
}

\begin{abstract}
Background While there have been no new medications approved for the treatment of Alzheimer's disease (AD) or other dementias in Canada since 2004, the Canadian Consensus Conference on the Diagnosis and Treatment of Dementia (CCCDTD) reviewed and updated the clinical practice guidelines on the pharmacological management of dementia that were published previously.

Methods This review focused on the literature for the pharmacological treatment of dementia based on studies published since the third CCCDTD in 2006. A literature search of English-language medical databases was preformed for studies pertaining to the pharmacological treatment of $A D$ and other dementias that examined the management of cognitive and functional impairment, as well as neuropsychiatric symptoms. All previous recommendations were reviewed, and only those that required updating based on new published studies were revised. Several new recommendations were also added. Recommendations were rated for quality of evidence and were approved by consensus.

Results There were 15 revised or new recommendations approved by consensus. The revised recommendations included acknowledging that cholinesterase inhibitors (ChEls) possess a class effect and any of the agents can be used for AD across the spectrum of severity and with co-existing cerebrovascular disease. There was insufficient evidence to recommend for or against the use of ChEls in combination with memantine for the primary indication of treating neuropsychiatric symptoms, or for the treatment of vascular dementia. Recommendations for the discontinuation of cognitive enhancers were revised and clarified, as well as the risks associated with discontinuing these drugs. ChEls were recommended as a treatment option for dementia with Parkinson's disease. Risks associated with use of antipsychotics for neuropsychiatric symptoms were strengthened, and guidelines regarding the use of antidepressants for affective disturbances in dementia were weakened, and are now considered an option but not a firm recommendation. Valproate was recommended not to be used, and there was insufficient evidence to recommend for or against the use of selective serotonin reuptake inhibitors or trazodone for the treatment of agitation and aggression.
\end{abstract}

Conclusion In spite of the lack of new therapeutic agents for the treatment of dementia, recent studies have helped to clarify and strengthen recommendations to optimize the pharmacological management of these illnesses.

\section{Background}

Alzheimer's disease (AD) and other dementias are prevalent illnesses that represent a dramatic burden to individuals, their families and society. Worldwide there are

*Correspondence: nathan.herrmann@sunnybrook.ca

'Department of Psychiatry and the Brain Sciences Research Program, Sunnybrook Health Sciences Centre, Suite FG08, 2075 Bayview Avenue, Toronto, Ontario M4N 3M5, Canada

Full list of author information is available at the end of the article currently 25 to 35 million individuals with these illnesses, with 5 to 7 million new cases diagnosed each year, or one new case every 7 seconds [1,2]. In Canada the estimated 500,000 individuals with dementia require about 231 million informal caregiver hours/year and cost $\$ 15$ billion/year [3]. To help patients, families and their physicians cope with these illnesses, numerous clinical practice guidelines have been developed [4-6].

The third Canadian Consensus Conference on the Diagnosis and Treatment of Dementia (CCCDTD) met in 2006 and published guidelines in 2007 and 2008. The 
fourth CCCDTD convened in spring 2012 and focused on proposed changes in diagnosis and nomenclature, as well as emerging data on biomarkers. Since no new medications had been approved in Canada since the last CCCDTD, a working group was formed to review the previous pharmacological recommendations and revise where necessary, given new data from randomized controlled trials (RCTs). Particular attention was paid to recommendations pertaining to combination treatment with cognitive enhancers and to recommendations related to discontinuing cognitive enhancers. The background for the revised recommendations that were proposed, and the final recommendations, approved by the CCCDTD in May 2012, are presented.

\section{Methods}

Details describing the guideline-creation process of the CCCDTD have been published previously $[7,8]$. Briefly, the consensus conference adhered to the methods of the AGREE collaboration [9]. For this update, the working group reviewed the previous pharmacological recommendations from each working group of CCCDTD3 [1014]. A literature search was conducted with PubMed and Embase, examining articles published from January 2006 until April 2012. Major search terms included 'dementia' OR 'Alzheimer's disease' AND 'therapy' OR 'treatment' with secondary terms, which included cognitive enhancers, cholinesterase inhibitors (ChEIs), donepezil, galantamine, rivastigmine, memantine, agitation, aggression, anxiety, apathy, depression, psychosis, delusions, hallucinations, sleep, appetite, antidepressants, antipsychotics, anxiolytics, sedatives, hypnotics, anticonvulsants.

The completed background papers were provided to all consensus conference delegates for comment and to suggest revisions and then recommendations were presented at the consensus conference. Final recommendations required $80 \%$ or more of the delegates voting for the recommendation to be approved. The evidence was graded both numerically by strength of recommendation ( 1 = strong, recommended; 2 = weak, suggested $)$ and then alphabetically by quality of evidence $(\mathrm{A}=$ high, $\mathrm{B}=$ moderate, $C=$ low) - such that $1 \mathrm{~A}$ suggests the recommendations would apply to most patients with no further research needed, whereas $2 \mathrm{C}$ implies that other alternatives are reasonable and higher quality research may impact the recommendation, as suggested by Guyatt and colleagues [15].

\section{Results}

All 14 recommendations proposed by the workgroup were approved by consensus. There were 11 recommendations from the previously published guidelines that were revised and three new recommendations. Nine of the recommendations underwent minor wording changes. Additionally, Consensus Conference delegates approved an extra recommendation related to the use of quetiapine for agitation and aggression. The final CCCDTD 2012 recommendations are presented in Table 1.

\section{New recommendation for the management of Alzheimer's disease}

- New recommendation Many cases of dementia have more than one condition contributing to causation. Most commonly this will be a combination of AD with other brain pathology. The recommendation is that management be based on what is (are) felt to be the predominant contributing cause(s). (Grade 1B)

\section{Rationale}

Dementia frequently arises from more than one condition [16-19]. For example, in the Rush Memory and Aging Study, 38\% of patients had AD and infarcts, 30\% had pure $\mathrm{AD}, 12 \%$ had vascular dementia (VaD) and $12 \%$ had AD with either Parkinson's disease (PD) or Lewy body dementia at autopsy [20]. In the BrainNet Europe Consortium, $53.3 \%$ of patients had mixed diagnoses among all cases of dementia [21]. The presence of multiple brain pathologies markedly increases the odds of cognitive impairment becoming evident [20,22].

In their clinical practice guideline for dementia, the National Institute for Health and Clinical Excellence noted the high prevalence of mixed pathology and suggested management according to the predominant cause [23]. This recommendation recognizes how commonly mixed pathologies underlie dementia and gives management advice to practicing physicians.

\section{Revised recommendation for management of Alzheimer's disease and cerebrovascular disease}

- Previous recommendation There is fair evidence for benefits of small magnitude for galantamine in cognitive, functional, behavioral, and global measures in AD with cerebrovascular disease. Galantamine can be considered a treatment option for mixed AD with cerebrovascular disease [14].

- Revised recommendation ChEIs are recommended as a treatment option for AD disease with cerebrovascular disease. (Grade 1B)

\section{Rationale}

$\mathrm{AD}$ and cerebrovascular lesions are frequently coidentified; for example, 37.5\% (30/80) of those with intermediate or high likelihood of $\mathrm{AD}$ in a communitybased clinical-pathologic cohort study [20]. In accord with the preceding new recommendation, ChEIs and/or memantine to deal with the AD component would be treatment considerations for these cases. The prior recommendation that singled out galantamine was based 


\section{Table 1. Summary of approved recommendations}

- Many cases of dementia have more than one condition contributing to causation. Most commonly this will be a combination of AD with other brain pathology. We recommend management be based on those diagnoses that are believed to be the predominant contributing cause(s). (Grade 1B)

- We recommend ChEls as a treatment option for AD with cerebrovascular disease. (Grade 1B)

- We recommend ChEls as a treatment option for dementia associated with Parkinson's disease. (Grade 1A)

- There is insufficient and inconsistent evidence on which to make a recommendation either for or against the use of the currently available ChEls for the treatment of vascular dementia. (Grade 2B)

- All three ChEls have demonstrated efficacy for mild to severe AD. We recommend a trial of a ChEls for most patients with AD. (Grade 1A)

- Direct comparisons do not suggest differences between ChEls (Grade 2B). Selection of which agent to be used will be based on the adverse effect profile, ease of use, familiarity, and differences between the agents in their pharmacokinetics and other mechanisms of action.

- There is insufficient evidence to recommend for or against the combination of a ChEl and memantine. (Grade 2B)

- Discontinuing ChEls in patients with moderate to severe AD may lead to worsening of cognitive function and greater functional impairment as compared with continued therapy (Grade 2B). This risk must be balanced with the risk for known side-effects and drug costs if therapy continues. It is suggested that ChEls be discontinued when:

(i) the patient and/or their proxy decision-maker decide to stop after being appraised of the risks and benefits of continuation and discontinuation;

(ii) the patient is sufficiently nonadherent with the medication that continued prescription of it would be useless, and it is not possible to establish a system for the administration of the medication to rectify the problem;

(iii) the patient's rate of cognitive, functional, and/or behavioral decline is greater on treatment compared with that prior to being treated;

(iv) the patient experiences intolerable side effects that are definitely or probably related to the ChEl;

(v) the comorbidities of the patient make continued use of the agent either unacceptably risky or futile (for example, terminally ill); or

(vi) the patient's dementia progresses to a stage (for example, Global Deterioration Scale stage 7) where there would be no clinically meaningful benefit from continued therapy.

- When a decision has been made to discontinue therapy because of a perceived lack of effectiveness, the suggestion is that the dose be tapered before stopping the agent and that the patient be monitored over the next 1 to 3 months for evidence of an observable decline. If this decline occurs, it is suggested that consideration be given to reinstating therapy. (Grade 2C)

- If the patient had an inadequate response to the nonpharmacological interventions or has a major depressive disorder, severe dysthymia or severe emotional lability, we recommend that a trial of an antidepressant could be considered. (Grade 2A)

- $\quad$ Based on good evidence we recommend that valproate should not be used for agitation and aggression in AD. (Grade 1A)

- There is insufficient evidence to recommend for or against the use of ChEls and/or memantine for the treatment of neuropsychiatric symptoms as a primary indication. (Grade 2B)

- We recommend that risperidone, olanzapine and aripiprazole be used for severe agitation, aggression and psychosis associated with dementia where there is risk of harm to the patient and/or others. The potential benefit of all antipsychotics must be weighed against the significant risks, such as cerebrovascular adverse events and mortality. (Grade 2A)

- There is insufficient evidence to recommend for or against the use of quetiapine in the management of severe agitation, aggression and psychosis associated with dementia. (Grade 2B)

- There is insufficient evidence to recommend for or against the use of selective serotonin reuptake inhibitors or trazodone in the management of agitated patients. (Grade 2B)

AD, Alzheimer's disease; ChEl, cholinesterase inhibitor.

on a subgroup analysis from a RCT in those with $\mathrm{AD}$ and cerebrovascular disease that was not replicated [24]. The Cochrane Review on the use of galantamine for vascular cognitive impairment concluded that 'More studies are needed before firm conclusions can be drawn' about its use [25].

There is evidence that other ChEIs can be beneficial in this form of mixed dementia. Subgroup analyses of the AD2000 study showed greater cognitive response in patients with $\mathrm{AD}$ and a vascular component than without $(P=0.02)$ [26]. A RCT of rivastigmine in patients with $\mathrm{AD}$ showed generally larger treatment effects in those with Modified Hachinski Ischemia Scores $\geq 1$ [27]. An open-label study of rivastigmine in patients with mixed dementia also showed benefit. In the VantagE study, older patients with a higher likelihood of concurrent AD demonstrated a significant cognitive response while younger patients showed none $[28,29]$.
The benefits seen with ChEIs in the treatment of dementia where both cerebrovascular disease and $\mathrm{AD}$ are felt to be significant contributing factors could result from treating the $\mathrm{AD}$ component. If this is the case, there is no reason to single out galantamine as the ChEI of choice because benefits are most probably a class effect. Although no ChEI in Canada has been specifically approved for the treatment of mixed dementia, in situations where both $\mathrm{AD}$ and cerebrovascular disease are felt to be making significant contributions to the dementia then a ChEI to deal with the AD contribution would be a treatment consideration.

\section{New recommendation for dementia associated with Parkinson's disease}

- New recommendation ChEIs are recommended as a treatment option for dementia associated with PD. (Grade 1A) 


\section{Rationale}

In a placebo-controlled study, treatment with rivastigmine was associated with moderate improvements in dementia associated with PD [30]. Two small randomized studies of subjects with PD and dementia showed that donepezil was well tolerated, did not worsen PD and was associated with modest benefits in cognition and global functioning [31,32].

The American Academy of Neurology Practice Parameter dealing with the treatment of dementia in PD concluded that donepezil and rivastigmine should be considered for the treatment of dementia in PD. Those recommendations are currently being updated [33]. The conclusion of a Cochrane Systematic Review was that 'The currently available evidence supports the use of ChEIs inhibitors in patients with PD dementia, with a positive impact on global assessment, cognitive function, behavioural disturbance and activities of daily living rating scales' [34].

Symptomatic treatment of patients with idiopathic PD and mild to moderate dementia is included as an indication in the revised 2011 Canadian drug monograph for rivastigmine, and can be found in the 2011 and 2012 editions of the Compendium of Pharmaceuticals and Specialties $[35,36]$. The working group's opinion was that the benefits seen are from a class effect of ChEIs.

\section{Revised recommendation for management of vascular dementia}

- Previous recommendation Use of ChEIs in probable/ possible $\mathrm{VaD}$ using the National Institute of Neurological Disorders and Stroke and Association Internationale pour la Recherche et l'Enseignement en Neurosciences diagnostic criteria: (a) there is insufficient evidence for or against the use of galantamine; and (b) there is fair evidence of benefits of small magnitude for donepezil in cognitive and global outcomes, with less robust benefits on functional measures. Donepezil can be considered a treatment option for $\mathrm{VaD}[14]$.

- Revised recommendation There is insufficient and inconsistent evidence on which to make a recommendation either for or against the use of the currently available ChEIs for the treatment of probable or possible VaD. (Grade $2 \mathrm{~B}$ )

\section{Rationale}

In a randomized, double-blind, placebo-controlled, parallel-group clinical trial of 788 patients with probable $\mathrm{VaD}$, galantamine did not lead to a statistically significant benefit on both co-primary endpoints; that is, the Alzheimer's Disease Assessment Scale - cognitive subscale (ADAS-Cog), and the Alzheimer's Disease Cooperative Study - Activities of Daily Living Inventory total score. After 26 weeks, those patients treated with galantamine had a small but greater improvement in ADAS-cog/11 but not on the Alzheimer's Disease Cooperative Study - Activities of Daily Living score. Safety data revealed that $13 \%$ of galantamine patients and $6 \%$ of placebo patients discontinued treatment because of adverse events [37]. Erkinjuntti and colleagues randomly allocated patients with either probable $\mathrm{VaD}$ or $\mathrm{AD}$ and cerebrovascular disease to galantamine or placebo. In those patients with probable $\mathrm{VaD}$, no statistically significant benefit was seen on either of the two primary outcome measures (ADAS-cog and Clinician's Interview Based Impression of Change plus caregiver input) [24].

There are three published clinical trials of donepezil for probable or possible $\mathrm{VaD}$ [38-40]. Donepezil was not shown to be an effective agent in two of these studies. In two of the three studies reviewed in the Canadian product monograph for donepezil, numerically higher mortality was found among patients treated with donepezil (statistically significant in one study). For the three trials combined, the mortality rate during doubleblind treatment was numerically but not significantly higher in the donepezil group [41].

A 24-week, multicenter, double-blind study of patients with probable $\mathrm{VaD}$ demonstrated superiority of rivastigmine over placebo on cognition (Vascular Dementia Assessment Scale, ADAS-Cog, and Mini-Mental State Examination (MMSE)) but not on activities of daily living or neuropsychiatric symptoms. The efficacy apparent on the cognitive outcomes was seen only in older patients who were more likely to have concomitant AD pathology, supporting the argument that the putative cholinergic deficit seen in $\mathrm{VaD}$ reflects the presence of concomitant AD pathology [28].

These studies do not show statistically significant benefits in function, neuropsychiatric symptoms or global status on a consistent basis. There were consistent but modest cognitive benefits (about 1.5 to 2 points on the ADAS-Cog) of uncertain clinical significance. No ChEI in Canada has been specifically approved for VaD. A methodological issue in the trials reviewed has been the difficulty in diagnosing 'pure' VaD as the criteria used are relatively insensitive (that is, will miss a proportion of those with significant cerebrovascular disease) and many of those fulfilling probable $\mathrm{VaD}$ criteria have mixed pathologies (typically $\mathrm{AD}$ and cerebrovascular disease) [42].

\section{Revised recommendations for the management of mild to severe Alzheimer's disease}

- Previous recommendation All three ChEIs available in Canada are modestly efficacious for mild to moderate AD. These ChEIs are all viable treatment options for most patients with mild to moderate AD [12]. 
- Revised recommendation All three ChEIs have demonstrated efficacy for mild to severe AD. A trial of a ChEI is recommended for most patients with $\mathrm{AD}$. (Grade 1A)

\section{Rationale}

As per the third CCCDTD, randomized placebocontrolled, double-blind trials supported the efficacy of all three ChEIs for mild to moderate dementia, with one additionally demonstrating efficacy for moderate to severe $\mathrm{AD}[43,44]$. The patient numbers needed to treat and to harm are similar [45]. There is better awareness of syncope [46] and bradycardia [47] from cohort studies. The recommendation for a trial of ChEIs in mild to moderate $\mathrm{AD}$ remains unchanged.

Since the third CCCDTD, new information has emerged on the indication for severe $\mathrm{AD}$ (commonly considered MMSE <10). RCTs have demonstrated efficacy in severe $\mathrm{AD}$ for donepezil [48-52], rivastigmine (secondary analysis only) [53] and galantamine (MMSE 5 to 12) [54]. The DOMINO trial assigned 295 community-dwelling patients with moderate or severe AD (MMSE 5 to 13) stabilized on donepezil to continued donepezil monotherapy, combined donepezil and memantine therapy, memantine monotherapy, or no active therapy for 52 weeks. Those patients randomized to continue donepezil versus discontinue donepezil had higher scores on cognition and function after adjustment for center, duration of donepezil treatment before entry, baseline MMSE and age [55].

- Previous recommendation While all three ChEIs available in Canada have efficacy for mild to moderate $\mathrm{AD}$, equivalency has not been established in direct comparisons. Selection of which agent to be used will be based on the adverse effect profile, ease of use, familiarity and beliefs about the importance of the differences between the agents in their pharmacokinetics and other mechanisms of action [12].

- Revised recommendation Direct comparisons do not suggest differences between ChEIs (Grade 2B). Selection of which agent to be used will be based on the adverse effect profile, ease of use, familiarity and beliefs about the importance of the differences between the agents in their pharmacokinetics and other mechanisms of action.

\section{Rationale}

Studies have presented four head-to-head comparisons of ChEI, with donepezil being compared with both rivastigmine $[56,57]$ and galantamine $[58,59]$. These randomized open-label, rater-blinded trials show similar benefits, but they are methodologically limited. Criticisms included a lack of double-blinding, small sample sizes, suboptimal dosing regimens and short treatment durations [60]. These data were available for the third CCCDTD except for Bullock and colleagues [56], which was a 24-month, larger $(n=994)$, doubleblind, flexible-dose study in patients with moderate to severe AD (MMSE 10 to 20). Similar to the previous studies, the two ChEIs were similar on measures of cognition and behavior. While rivastigmine showed possible advantages on activities of daily living and global function, the results were not consistent. Adverse events were similar. The more recent trial supports the previous recommendation that there are no differences between ChEIs.

- Previous recommendation for mild to moderate AD Combination therapy of a ChEI and memantine is rational (as the medications have different mechanisms of action), appears to be safe, and may lead to additional benefits for patients with moderate to severe AD. This would be an option for patients with AD of a moderate severity [12].

- Previous recommendation for severe $A D$ Patients with severe $\mathrm{AD}$ can be treated with ChEIs, memantine or the combination. Expected benefits would include modest improvements in cognition, function and behavior and/or slower decline [13].

- Revised recommendation There is insufficient evidence to recommend for or against the combination of a ChEI and memantine (Grade 2B)

\section{Rationale}

While the first published trial by Tariot and colleagues adding memantine or placebo to donepezil in moderate to severe $\mathrm{AD}(n=404)$ was supportive [61], subsequent trials by Porsteinsson and colleagues in mild to moderate patients [62] and the DOMINO trial in moderate to severe patients [55] were not. Porsteinsson and colleagues studied 433 participants with mild to moderate AD (MMSE 10 to 22) who were stable on any of the three ChEIs and were randomized to receive placebo or memantine ( $20 \mathrm{mg}$ once daily) for 24 weeks. They found no significant differences between the memantine and placebo groups on cognition, function or behavior, and tolerability was similar. The DOMINO trial $(n=295)$ found no benefits in cognition in those patients randomized to donepezil and memantine ( $n=72,38$ completers) versus donepezil alone ( $n=73,34$ completers), after adjustment for center, duration of donepezil treatment before entry, baseline MMSE and age [55]. There were no differences between groups in serious adverse events. Overall, while the combination appears safe, there is insufficient evidence of additional efficacy.

The recommendation for memantine monotherapy from the previous consensus conference is still considered valid: memantine is an option for patients with moderate to severe stages of $\mathrm{AD}$. Use of memantine in mild stages of $\mathrm{AD}$ is not recommended [63]. 
- Previous recommendations referring to discontinuation of therapy with ChEIs and memantine Medications for the treatment of cognitive and functional manifestations of $\mathrm{AD}$ should be discontinued when: the patient and/or their proxy decision-maker decides to stop; the patient refuses to take the medication; the patient is sufficiently nonadherent with the medication that continued prescription of it would be useless, and it is not possible to establish a system for the administration of the medication to rectify the problem; there is no response to therapy after a reasonable trial; the patient experiences intolerable side effects; the comorbidities of the patient make continued use of the agent either unacceptably risky or futile (for example, terminally ill); or the patient's dementia progresses to a stage where there is no significant benefit from continued therapy [12].

After stopping therapy for AD, patients should be carefully monitored - if there is evidence of a significant decline in their cognitive status or functional abilities or the development/worsening of behavioral challenges, consideration should be given to reinstating the therapy [12].

Treatment with ChEIs and/or memantine should persist until clinical benefit can no longer be demonstrated. Treatment should not be discontinued simply because of institutionalization [13].

- Revised recommendations Discontinuing ChEIs in patients with moderate to severe $\mathrm{AD}$ may lead to worse cognitive function and greater functional impairment as compared with continued therapy (Grade 2B). This effect must be balanced with the risk for known sideeffects and drug costs if therapy continues. ChEIs should be discontinued when:

(i) the patient and/or their proxy decision-maker decide to stop after being appraised of the risks and benefits of continuation and discontinuation;

(ii) the patient refuses to take the medication;

(iii) the patient is sufficiently nonadherent with the medication that continued prescription of it would be useless, and it is not possible to establish a system for the administration of the medication to rectify the problem;

(iv) the patient's rate of cognitive, functional and/or behavioral decline is greater on treatment compared with that prior to being treated;

(v) the patient experiences intolerable side effects that are definitely or probably related to the ChEI;

(vi) the comorbidities of the patient make continued use of the agent either unacceptably risky or futile (for example, terminally ill); or

(vii) the patient's dementia progresses to a stage (for example, Global Deterioration Scale stage 7 [64]) where there would be no clinically meaningful benefit from continued therapy.
When a decision has been made to discontinue therapy because of a perceived lack of effectiveness, the dose should be tapered before stopping the agent and the patient should be monitored over the next 1 to 3 months for evidence of significant decline. If decline occurs, it is suggested consideration be given to reinstating therapy. (Grade $2 \mathrm{C}$ )

\section{Rationale}

After treatment with a ChEI is started, the likelihood of stopping within a year is high [65]. When this cessation is done on the basis of patient/caregiver preference or adverse events, these decisions are in general not controversial. The one qualification to this statement relates to stopping because of adverse events. In many older patients, possible adverse events that emerge during therapy could be due to alternative causes. Before acting, an assessment of the probability that the adverse event is related to therapy should be made [66].

A persisting area of uncertainty is when to discontinue a ChEI because of a perceived lack of clinically relevant benefit. There is agreement that these decisions should be individualized and based on clinical judgment rather than arbitrarily stopping once a patient scores less than a predefined threshold on a brief cognitive measure such as the MMSE or is institutionalized [12,13]. An Internet-based survey of Canadian dementia experts (geriatric psychiatrists, geriatricians, neurologists) on when to discontinue $\mathrm{ChEI}$ therapy led to a number of recommendations where there was reasonable consensus among the respondents [67].

The DOMINO study provides RCT data on the consequences of discontinuing therapy with a ChEI (donepezil) in patients with moderate to severe AD [55]. After a year, those patients who continued therapy scored on average 1.9 points higher on a Standardized MMSE and 3 points better on the Bristol Activities of Daily Living Scale. Similar data exist for ChEIs in mild to moderate AD [68]. Some patients show withdrawal phenomena after stopping a ChEI [69]. Although there is no rigorous research data to support the suggestion, some recommend tapering before stopping [67]. Older studies suggested that interrupting therapy for prolonged periods of time (for example, 6 weeks) could result in the loss of treatment benefits that could not be recaptured [70]. This would suggest that if a decision is made to restart after stopping a ChEI, it would be better to do so earlier rather than later.

\section{Revised recommendation for the management of mood disorders associated with Alzheimer's disease}

- Previous recommendation If the patient had an inadequate response to the nonpharmacological interventions or has a major affective disorder, severe dysthymia or severe emotional lability, a trial of an antidepressant should be considered [13]. 
- Revised recommendation If the patient had an inadequate response to the nonpharmacological interventions or has a major affective disorder, severe dysthymia or severe emotional lability, a trial of an antidepressant could be considered. (Grade 2A)

\section{Rationale}

At the time of the third CCCDTD there was reasonable evidence to support this recommendation. For example, a meta-analysis of the RCTs of antidepressants for treatment of depression in $\mathrm{AD}$ concluded that treatment was efficacious with discontinuation rates that were equivalent to placebo [71]. Since then, two large RCTs on the treatment of depression in dementia have shown benefits equivalent to placebo. Using the provisional diagnostic criteria for depression in AD [72], the DIADS-2 study compared 131 patients randomized to sertraline or placebo for 12 weeks [73]. Both groups experienced significant and similar reductions in depressive symptoms, although the sertraline-treated group experienced more adverse events. Similarly, in the HTA-SADD study, 218 patients judged clinically to have depression requiring antidepressant treatment were randomized to treatment with mirtazapine, sertraline or placebo [74]. At both 13-week and 39-week follow-ups, all three groups experienced significant and similar declines in depression rating scores, although the patients treated with active drug experienced significantly more adverse events. While both studies appear to confirm that depression in $\mathrm{AD}$ responds to treatment, it is unclear whether treatment with antidepressants is better than psychosocial interventions and whether treatment with active drug is clearly associated with adverse effects. Finally, while there is evidence that depression and depressive symptoms are persistent in many patients, the significant variability supports spontaneous remission of symptoms in some individuals $[75,76]$.

Given data from newer studies, the working group suggested the recommendation should be modified. The original recommendations were wisely worded to indicate that nonpharmacological interventions should precede medications, however, and antidepressants could still be considered an option in cases where nonpharmacological interventions have failed. As noted in the previous guidelines, preference should be given to the selective serotonin reuptake inhibitors (SSRIs) and tricyclic antidepressants should be avoided because of their anticholinergic effects and resultant concerns about worsening cognition.[77]

\section{New recommendation for the management of agitation} and aggression in Alzheimer's disease

- New recommendation There is good evidence that valproate should not be used for agitation and aggression in $\mathrm{AD}$. (Grade 1A)

\section{Rationale}

At the time of publication of the third CCCDTD, five RCTs had examined the efficacy of valproate preparations for agitation and aggression in patients with dementia [78], with none showing efficacy on any of the primary outcome measures although some of the secondary outcome measures were positive. Valproate was associated with significant adverse events and dropouts. More recently, the Alzheimer's Disease Cooperative Study published results of a large RCT of divalproex sodium for prevention of the emergence of agitation or psychosis in mild to moderate AD [79]. This 24-month randomized placebo-controlled study of 313 patients showed no differences in the emergence of neuropsychiatric symptoms, and divalproex sodium was poorly tolerated with significant toxicity. Even more worrisome, patients treated with divalproex in a substudy were found to experience accelerated brain volume loss and greater cognitive impairment compared with placebo-treated patients [80]. Finally, in a recently published administrative health database study, valproate appeared to have a similar risk of mortality in dementia patients compared with haloperidol, risperidone and olanzapine [81].

\section{Revised recommendations for management of neuropsychiatric symptoms}

- Previous recommendation Patients who have mild to moderate AD and neuropsychiatric symptoms can be considered for a trial of a ChEI and/or memantine for these symptoms [12].

- Revised recommendation There is insufficient evidence to recommend for or against the use of ChEIs and/or memantine for the treatment of neuropsychiatric symptoms as a primary indication. (Grade $2 \mathrm{~B}$ )

\section{Rationale}

At the time of the third CCCDTD this recommendation was supported by secondary outcome measures reported from pivotal trials of cognitive enhancers in patients with low levels of neuropsychiatric symptoms at baseline. There was also one randomized placebo-controlled withdrawal study of donepezil, which demonstrated efficacy for the treatment of neuropsychiatric symptoms in mild to moderate $\mathrm{AD}$ patients with moderate levels of neuropsychiatric symptoms at baseline [82]. Subsequently, a large well-designed RCT of donepezil was conducted in patients with significant agitation at baseline that demonstrated no significant benefit compared with placebo [83]. This study, however, provided a powerful psychosocial intervention to both groups that may have contributed to the lack of demonstrable drug-placebo differences. With respect to memantine, the results of a large Canadian RCT were recently presented [84]. In this study of over $300 \mathrm{AD}$ patients with significant agitation at 
baseline, there were no differences on any of the neuropsychiatric outcome measures compared with placebo.

- Previous recommendation Risperidone and olanzapine can be used for severe agitation, aggression and psychosis. The potential benefit of all antipsychotics must be weighed against the potential risks such as cerebrovascular adverse events and mortality [13].

- Revised recommendation Risperidone, olanzapine and aripiprazole can be used for severe agitation, aggression and psychosis where there is risk of harm to the patient and/or others. The potential benefit of all antipsychotics must be weighed against the significant risks such as cerebrovascular adverse events and mortality. (Grade 2A)

\section{Rationale}

At the time of publication of the third CCCDTD, aripiprazole was not approved for use in Canada, although it subsequently became available in 2009. Three RCTs comparing aripiprazole with placebo in AD patients for treatment of agitation and psychosis demonstrated reasonable tolerability and benefits significantly greater than placebo [85-87]. In a meta-analysis of these trials, the pooled estimate of effect sizes was small but statistically significant and similar to benefits found with risperidone and olanzapine [88].

While Health Canada warnings for increased rates of cerebrovascular adverse events and mortality based on the RCTs of the atypical antipsychotics had already been published at the time of the third CCCDTD and were carefully considered, subsequent RCTs and data from large administrative health databases raise further concerns about the safety of the antipsychotics in older dementia patients. These concerns include cognitive decline [89], adverse metabolic effects [90,91], and extrapyramidal symptoms [92]. Similarly, newer studies appear to confirm the risk of excess mortality in antipsychotic-treated patients with dementia, although different antipsychotics may have relatively different risks and some other nonantipsychotic drugs may carry similar risks [93-96].

- Previous recommendation There is insufficient evidence to recommend for or against the use of trazodone in the management of nonpsychotic, agitated patients [13].

- Revised recommendation There is insufficient evidence to recommend for or against the use of SSRIs or trazodone in the management of agitated patients. (Grade 2B)

\section{Rationale}

There have been two recent double-blind RCTs that compared citalopram [97] and escitalopram [98] with risperidone in moderate to severe $\mathrm{AD}$ patients with significant behavioral and psychological symptoms of dementia. Both SSRIs demonstrated efficacy that was similar to risperidone, but with better tolerability. In a randomized placebo-controlled trial of SSRI antidepressant discontinuation in nondepressed nursing home residents with dementia, discontinuation was associated with significant increases in depression rating scale scores although scores for agitation and psychosis were similar [99]. A recent Cochrane Review concluded that while larger randomized placebo-controlled studies are needed, the SSRIs and trazodone appear to be reasonably well tolerated when compared with placebo and typical and atypical antipsychotics [100].

\section{Discussion}

All of the recommendations from the working group on the updated pharmacological treatment of dementia were approved by consensus. Some recommendations underwent minor wording changes for consistency or in response to input from other working groups.

As noted in Table 1, at CCCDTD 2012 another recommendation was added, which suggested that there was insufficient evidence for or against the use of quetiapine for severe agitation, aggression or psychosis associated with dementia. Participants argued for inclusion of this guideline recognizing the significant increase in frequency of use of quetiapine for these indications in the past few years. Whether this increase was due to the fact that, unlike risperidone and olanzapine, there were no Health Canada warnings about increased cerebrovascular adverse events in dementia trials with quetiapine or whether it was because of perceived advantages with respect to the development of extrapyramidal effects is unclear [101]. While previous reviews and meta-analyses concluded there was no evidence of efficacy for quetiapine for behavioral and psychological symptoms of dementia in $\mathrm{AD}[75,102]$, a recent meta-analysis suggested somewhat different results [103]. In that metaanalysis of six RCTs, quetiapine was found to have statistically significant greater benefit than placebo on behavioral measures and clinical global impression. Interestingly, in spite of these findings, those authors concluded that the current literature does not support the use of quetiapine for behavioral and psychological symptoms of dementia. One should also note that, unlike the positive trials of clozapine for the treatment of psychosis in dementia with PD, RCTs of quetiapine for PD have demonstrated mixed (mostly negative) results, and recent evidence-based clinical practice guidelines from the Movement Disorders Society consider the use of quetiapine only 'investigational' at the present time [104].

One potential advantage for the use of quetiapine relates to greater dose flexibility, which might be 
particularly helpful for very old and frail individuals. For example, while use of the other recommended atypical antipsychotics falls within tight dose ranges related to their high potency (for example, risperidone 0.5 to $2.0 \mathrm{mg}$, olanzapine 5 to $10 \mathrm{mg}$, aripiprazole 5 to $15 \mathrm{mg}$ ), quetiapine, a low potency drug, can be titrated by $25 \mathrm{mg}$ increments from 25 to $300 \mathrm{mg} /$ day [6].

While beyond the mandate of the workgroup, a potential limitation of the guidelines was a lack of recommendations for the pharmacological management of other dementias, such as frontotemporal dementias. There are no approved therapies for frontotemporal dementias in Canada, and recent reviews have emphasized that the limited and conflicting nature of the available data makes the role of pharmacological management uncertain [105]. The workgroup identified seven trials of cognitive enhancers in frontotemporal dementia patients, including four open-label or nonrandomized studies with ChEIs [106-109], one small, negative doubleblind placebo-controlled withdrawal study with galantamine [110], an open-label study with memantine [109], and a small negative randomized placebo-controlled trial with memantine [111]. There are also several open-label studies examining the use of antidepressants, psychostimulants and antipsychotics for neuropsychiatric symptoms [112-114], as well as three RCTs including a positive study with trazodone [115] and two small studies with contrasting results using paroxetine $[116,117]$.

Another potential limitation is that these guidelines do not mention specific doses or formulations for the ChEIs. As noted above, ChEIs are considered of equivalent efficacy, with tolerability considerations guiding clinicians in their choice. These recommendations would therefore extend to the transdermal patch formulation of rivastigmine [118]. The $23 \mathrm{mg}$ formulation of donepezil is not available in Canada and recommendations for its use were therefore not considered. One should, however, note that evidence for the tolerability and effectiveness of this dose has been controversial [119].

\section{Conclusion}

Since the third CCCDTD in 2006, the literature on new agents for the pharmacological management of $\mathrm{AD}$ and other dementias has been characterized by disappointing failures. Numerous therapeutic agents with rational mechanisms of action and positive findings in preclinical and even early phase II studies have shown disappointing results and have been abandoned [120]. These agents include drugs such as tramiprosate, flurbiprofen, glitazones, statins, dimebon, semagacestat and, most recently, bapineuzumab. These failures have left clinicians with therapies that have been generally available for over a decade, and provide modest benefits at best. In spite of this, we believe attempts to update treatment guidelines such as those presented are the best way to optimize therapy and provide patients, families and their physicians with the best and safest interventions available at the present time. Our hope is that, at the time of the next CCCDTD, more effective interventions including disease-modifying therapies will be available.

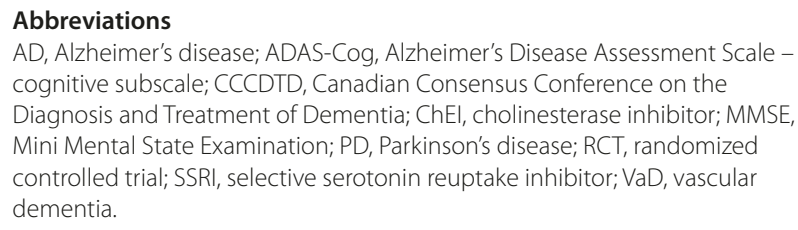

AD, Alzheimer's disease; ADAS-Cog, Alzheimer's Disease Assessment Scale cognitive subscale; CCCDTD, Canadian Consensus Conference on the Diagnosis and Treatment of Dementia; ChEl, cholinesterase inhibitor; MMSE, Mini Mental State Examination; PD, Parkinson's disease; RCT, randomized controlled trial; SSRI, selective serotonin reuptake inhibitor; VaD, vascular dementia.

\section{Competing interests}

$\mathrm{NH}$ has received research grants from Lundbeck, Sanofi-Aventis and Sonexa, and has also received honoraria from Lundbeck, Pfizer, Novartis and JanssenOrtho Inc. He was a consultant for Lundbeck, and also participated in a speaker forum for Lundbeck and Pfizer. He is a Board Member for Pfizer and Lundbeck. KLL has received grants/funds from Abbot Laboratories, Lundbeck, Pfizer, Janssen-Ortho Inc., Roche and Wyeth, and has also received honoraria from Abbot Laboratories, Lundbeck, Pfizer, Janssen-Ortho Inc., Medlmmune and Wyeth. She was also a consultant for Abbot Laboratories, Pfizer, JanssenOrtho Inc., Medlmmune and Wyeth. DBH holds and receives financial support from the Brenda Strafford Foundation Chair in Geriatric Medicine at the University of Calgary. He has no competing interests to declare.

\section{Declarations}

This article has been published as part of Alzheimer's Research \& Therapy Volume 5 Supplement 1, 2013: Background documents to the 4th Canadian Consensus Conference on the Diagnosis and Treatment of Dementia (CCCDTD4). The full contents of the supplement are available online at http://alzres.com/supplements/5/S1.

Publication charges for the supplement were funded by the Canadian Consensus Conference on the Diagnosis and Treatment of Dementia (CCCDTD). Although residual conference funds used include contributions from pharmaceutical companies, no commercial organization has been involved in the selection of participants, choice of topics, preparation of background papers or recommendations. In kind support was also provided by the Canadian Dementia Knowledge Translation Network, and the offices of Drs Serge Gauthier (McGill University), Christopher Patterson (McMaster University) and Howard Chertkow (McGill University), whose role as Guest Editors involved the coordination of the project without involvement in the journal's standard peer review process which applied for all articles.

\section{Author's contributions}

$\mathrm{NH}$ conceived of the design. All authors conducted the review, drafted the updated recommendations, and read and approved the final manuscript.

\section{Author details}

'Department of Psychiatry and the Brain Sciences Research Program, Sunnybrook Health Sciences Centre, Suite FG08, 2075 Bayview Avenue, Toronto, Ontario M4N 3M5, Canada. ${ }^{2}$ Department of Psychiatry, University of Toronto, Suite FG08, 2075 Bayview Avenue, Toronto, Ontario M4N 3M5, Canada. ${ }^{3}$ Department of Medicine and The Hotchkiss Brain Institute, University of Calgary, HSC-3330 Hospital Dr. NW, Calgary, Alberta T2N 4N1, Canada.

Published: 8 July 2013

\section{References}

1. World Health Organization: Dementia: A Public Health Priority. Geneva: WHO; 2012.

2. Ferri CP, Prince M, Brayne C, Brodaty H, Fratiglioni L, Ganguli M, Hall K, Hasegawa K, Hendrie H, Huang Y, Jorm A, Mathers C, Menezes PR, Rimmer E, Scazufca M: Global prevalence of dementia: a Delphi consensus study. Lancet 2005, 366:2112-2117.

3. Alzheimer Society of Canada: Rising Tide: The Impact of Dementia on Canadian Society. Toronto: Alzheimer Society of Canada; 2010. 
4. Hort J, O'Brien JT, Gainotti G, Pirttila T, Popescu BO, Rektorova I, Sorbi S, Scheltens P: EFNS guidelines for the diagnosis and management of Alzheimer's disease. Eur J Neurol 17:1236-1248.

5. Ihl R, Frolich L, Winblad B, Schneider L, Burns A, Moller HJ: World Federation of Societies of Biological Psychiatry (WFSBP) guidelines for the biological treatment of Alzheimer's disease and other dementias. World J Biol Psychiatry 12:2-32.

6. Rabins PV, Blacker D, Rovner BW, Rummans T, Schneider LS, Tariot PN, Blass DM, McIntyre JS, Charles SC, Anzia DJ, Cook IA, Finnerty MT, Johnson BR, Nininger JE, Schneidman B, Summergrad P, Woods SM, Berger J, Cross CD, Brandt HA, Margolis PM, Shemo JP, Blinder BJ, Duncan DL, Barnovitz MA, Carino AJ, Freyberg ZZ, Gray SH, Tonnu T, Kunkle R, et al: American Psychiatric Association practice guideline for the treatment of patients with Alzheimer's disease and other dementias. Second edition. Am J Psychiatry 2007, 164:5-56.

7. Chertkow H: Diagnosis and treatment of dementia: introduction. Introducing a series based on the Third Canadian Consensus Conference on the Diagnosis and Treatment of Dementia. CMAJ 2008, 178:316-321.

8. Gauthier S PC, Chertkow H, Gordon M, Herrmann N, Rockwood K, Rosa-Neto P, Soucy JP: 4th Canadian Consensus Conference on the Diagnosis and Treatment of Dementia. Can J Neurol Sci 2012, 39:S1-S8.

9. AGREE Collaboration: Development and validation of an international appraisal instrument for assessing the quality of clinical practice guidelines: the AGREE project. Qual Saf Health Care 2003, 12:18-23.

10. Patterson C, Feightner JW, Garcia A, Hsiung GY, MacKnight C, Sadovnick AD: Diagnosis and treatment of dementia: 1. Risk assessment and primary prevention of Alzheimer disease. CMAJ 2008, 178:548-556.

11. Chertkow H, Massoud F, Nasreddine Z, Belleville S, Joanette Y, Bocti C, Drolet $\mathrm{V}$, Kirk J, Freedman M, Bergman H: Diagnosis and treatment of dementia: 3. Mild cognitive impairment and cognitive impairment without dementia. CMAJ 2008, 178:1273-1285

12. Hogan DB, Bailey P, Black S, Carswell A, Chertkow H, Clarke B, Cohen C, Fisk JD, Forbes D, Man-Son-Hing M, Lanctôt K, Morgan D, Thorpe L: Diagnosis and treatment of dementia: 5. Nonpharmacologic and pharmacologic therapy for mild to moderate dementia. CMAJ 2008, 179:1019-1026.

13. Herrmann N, Gauthier S: Diagnosis and treatment of dementia: 6 . Management of severe Alzheimer disease. CMAJ 2008, 179:1279-1287.

14. Bocti C, Black S, Frank C: Management of dementia with a cerebrovascular component. Alzheimers Dement 2007, 3:398-403.

15. Guyatt GH, Cook DJ, Jaeschke R, Pauker SG, Schunemann HJ: Grades of recommendation for antithrombotic agents: American College of Chest Physicians Evidence-Based Clinical Practice Guidelines (8th edition). Chest 2008, 133:123S-131S

16. Fotuhi $M$, Hachinski V, Whitehouse PJ: Changing perspectives regarding late-life dementia. Nat Rev Neurol 2009, 5:649-658.

17. Schneider JA, Arvanitakis Z, Bang W, Bennett DA: Mixed brain pathologies account for most dementia cases in community-dwelling older persons. Neurology 2007, 69:2197-2204.

18. Kovacs GG, Alafuzoff I, Al-Sarraj S, Arzberger T, Bogdanovic N, Capellari S, Ferrer I, Gelpi E, Kovari V, Kretzschmar H, Nagy Z, Parchi P, Seilhean D, Soininen $\mathrm{H}$, Troakes C, Budka H: Mixed brain pathologies in dementia: the BrainNet Europe consortium experience. Dement Geriatr Cogn Disord 2008, 26:343-350.

19. Neuropathology Group of the Medical Research Council Cognitive Function and Ageing Study (MRC CFAS): Pathological correlates of late-onset dementia in a multicentre, community-based population in England and Wales. Neuropathology Group of the Medical Research Council Cognitive Function and Ageing Study (MRC CFAS). Lancet 2001, 357:169-175.

20. Sonnen JA, Larson EB, Crane PK, Haneuse S, Li G, Schellenberg GD, Craft S, Leverenz JB, Montine TJ: Pathological correlates of dementia in a longitudinal, population-based sample of aging. Ann Neurol 2007, 62:406-413.

21. White L, Small BJ, Petrovitch H, Ross GW, Masaki K, Abbott RD, Hardman J, Davis D, Nelson J, Markesbery W: Recent clinical-pathologic research on the causes of dementia in late life: update from the Honolulu-Asia Aging Study. J Geriatr Psychiatry Neurol 2005, 18:224-227.

22. Schneider JA, Arvanitakis Z, Leurgans SE, Bennett DA: The neuropathology of probable Alzheimer disease and mild cognitive impairment. Ann Neurol 2009, 66:200-208.

23. National Institute for Health and Clinical Excellence: Dementia: Supporting People with Dementia and their Carers in Health and Social Care. London: NICE;
2011:26.

24. Erkinjuntti T, Kurz A, Gauthier S, Bullock R, Lilienfeld S, Damaraju CV: Efficacy of galantamine in probable vascular dementia and Alzheimer's disease combined with cerebrovascular disease: a randomised trial. Lancet 2002, 359:1283-1290.

25. Craig D, Birks J: Galantamine for vascular cognitive impairment. Cochrane Database Syst Rev 2006, 1:CD004746.

26. Courtney C, Farrell D, Gray R, Hills R, Lynch L, Sellwood E, Edwards S, Hardyman W, Raftery J, Crome P, Lendon C, Shaw H, Bentham P: Long-term donepezil treatment in 565 patients with Alzheimer's disease (AD2000): randomised double-blind trial. Lancet 2004, 363:2105-2115.

27. Kumar V, Anand R, Messina J, Hartman R, Veach J: An efficacy and safety analysis of Exelon in Alzheimer's disease patients with concurrent vascular risk factors. Eur J Neurol 2000, 7:159-169.

28. Ballard C, Sauter M, Scheltens $P, H e Y$, Barkhof F, van Straaten EC, van der Flier WM, Hsu C, Wu S, Lane R: Efficacy, safety and tolerability of rivastigmine capsules in patients with probable vascular dementia: the VantagE study. Curr Med Res Opin 2008, 24:2561-2574.

29. Zekry D, Gold G: Management of mixed dementia. Drugs Aging 27:715-728.

30. Emre M, Aarsland D, Albanese A, Byrne EJ, Deuschl G, De Deyn PP, Durif F, Kulisevsky J, van Laar T, Lees A, Poewe W, Robillard A, Rosa MM, Wolters E, Quarg P, Tekin S, Lane R: Rivastigmine for dementia associated with Parkinson's disease. NEng/ J Med 2004, 351:2509-2518.

31. Aarsland D, Laake K, Larsen JP, Janvin C: Donepezil for cognitive impairment in Parkinson's disease: a randomised controlled study. J Neurol Neurosurg Psychiatry 2002, 72:708-712

32. Ravina B, Putt M, Siderowf A, Farrar JT, Gillespie M, Crawley A, Fernandez HH, Trieschmann MM, Reichwein S, Simuni T: Donepezil for dementia in Parkinson's disease: a randomised, double blind, placebo controlled, crossover study. J Neurol Neurosurg Psychiatry 2005, 76:934-939.

33. Miyasaki JM, Shannon K, Voon V, Ravina B, Kleiner-Fisman G, Anderson K, Shulman LM, Gronseth G, Weiner WJ: Practice parameter: evaluation and treatment of depression, psychosis, and dementia in Parkinson disease (an evidence-based review): report of the Quality Standards Subcommittee of the American Academy of Neurology. Neurology 2006, 66:996-1002

34. Rolinski M, Fox C, Maidment I, McShane R: Cholinesterase inhibitors for dementia with Lewy bodies, Parkinson's disease dementia and cognitive impairment in Parkinson's disease. Cochrane Database Syst Rev 2012, 3:CD006504.

35. Canadian Pharmacists Association: The Canadian Drug Reference for Health Professionals. Ottawa: Canadian Pharmacists Association; 2011:954.

36. Canadian Pharmacists Association: The Canadian Drug Reference for Health Professionals. Ottawa: Canadian Pharmacists Association; 2012:1024.

37. Auchus AP, Brashear HR, Salloway S, Korczyn AD, De Deyn PP, GassmannMayer C: Galantamine treatment of vascular dementia: a randomized trial. Neurology 2007, 69:448-458.

38. Wilkinson D, Doody R, Helme R, Taubman K, Mintzer J, Kertesz A, Pratt RD: Donepezil in vascular dementia: a randomized, placebo-controlled study. Neurology 2003, 61:479-486

39. Black S, Roman GC, Geldmacher DS, Salloway S, Hecker J, Burns A, Perdomo C, Kumar D, Pratt R: Efficacy and tolerability of donepezil in vascular dementia: positive results of a 24-week, multicenter, international, randomized, placebo-controlled clinical trial. Stroke 2003, 34:2323-2330.

40. Roman GC, Salloway S, Black SE, Royall DR, Decarli C, Weiner MW, Moline M, Kumar D, Schindler R, Posner H: Randomized, placebo-controlled, clinical trial of donepezil in vascular dementia: differential effects by hippocampal size. Stroke 2010, 41:1213-1221.

41. Canadian Pharmacists Association: The Canadian Drug Reference for Health Professionals. Ottawa: Canadian Pharmacists Association; 2012:268.

42. Holmes C, Cairns N, Lantos P, Mann A: Validity of current clinical criteria for Alzheimer's disease, vascular dementia and dementia with Lewy bodies. Br J Psychiatry 1999, 174:45-50.

43. Feldman H, Gauthier S, Hecker J, Vellas B, Subbiah P, Whalen E: A 24-week, randomized, double-blind study of donepezil in moderate to severe Alzheimer's disease. Neurology 2001, 57:613-620.

44. Gauthier S, Feldman H, Hecker J, Vellas B, Ames D, Subbiah P, Whalen E, Emir $B$ : Efficacy of donepezil on behavioral symptoms in patients with moderate to severe Alzheimer's disease. Int Psychogeriatr 2002, 14:389-404.

45. Lanctot KL, Herrmann N, Yau KK, Khan LR, Liu BA, LouLou MM, Einarson TR: Efficacy and safety of cholinesterase inhibitors in Alzheimer's disease: a 
meta-analysis. CMAJ 2003, 169:557-564.

46. Gill SS, Anderson GM, Fischer HD, Bell CM, Li P, Normand SL, Rochon PA: Syncope and its consequences in patients with dementia receiving cholinesterase inhibitors: a population-based cohort study. Arch Intern Med 2009, 169:867-873.

47. Park-Wyllie LY, Mamdani MM, Li P, Gill SS, Laupacis A, Juurlink DN: Cholinesterase inhibitors and hospitalization for bradycardia: a population-based study. PLoS Med 2009, 6:e1000157.

48. Black SE, Doody R, Li H, McRae T, Jambor KM, Xu Y, Sun Y, Perdomo CA Richardson S: Donepezil preserves cognition and global function in patients with severe Alzheimer disease. Neurology 2007, 69:459-469.

49. Homma A, Imai Y, Tago H, Asada T, Shigeta M, Iwamoto T, Takita M, Arimoto I, Koma H, Ohbayashi T: Donepezil treatment of patients with severe Alzheimer's disease in a Japanese population: results from a 24-week, double-blind, placebo-controlled, randomized trial. Dement Geriatr Cogn Disord 2008, 25:399-407.

50. Winblad B: Donepezil in severe Alzheimer's disease. Am J Alzheimers Dis Other Dement 2009, 24:185-192.

51. Winblad B, Black SE, Homma A, Schwam EM, Moline M, Xu Y, Perdomo CA, Swartz J, Albert K: Donepezil treatment in severe Alzheimer's disease: a pooled analysis of three clinical trials. Curr Med Res Opin 2009, 25:2577-2587.

52. Winblad B, Kilander L, Eriksson S, Minthon L, Batsman S, Wetterholm AL, Jansson-Blixt C, Haglund A: Donepezil in patients with severe Alzheimer's disease: double-blind, parallel-group, placebo-controlled study. Lancet 2006, 367:1057-1065.

53. Farlow MR, Grossberg GT, Meng X, Olin J, Somogyi M: Rivastigmine transdermal patch and capsule in Alzheimer's disease: influence of disease stage on response to therapy. Int J Geriatr Psychiatry 26:1236-1243.

54. Burns A, Bernabei R, Bullock R, Cruz Jentoft AJ, Frolich L, Hock C, Raivio M, Triau E, Vandewoude M, Wimo A, Came E, Van Baelen B, Hammond GL, van Oene JC, Schwalen S: Safety and efficacy of galantamine (Reminyl) in severe Alzheimer's disease (the SERAD study): a randomised, placebocontrolled, double-blind trial. Lancet Neurol 2009, 8:39-47.

55. Howard R, McShane R, Lindesay J, Ritchie C, Baldwin A, Barber R, Burns A, Dening T, Findlay D, Holmes C, Hughes A, Jacoby R, Jones R, Jones R, McKeith I, Macharouthu A, O'Brien J, Passmore P, Sheehan B, Juszczak E, Katona C, Hills R, Knapp M, Ballard C, Brown R, Banerjee S, Onions C, Griffin M, Adams J, Gray $\mathrm{R}$, et al: Donepezil and memantine for moderate-to-severe Alzheimer's disease. NEngl J Med 2012, 366:893-903.

56. Bullock R, Touchon J, Bergman H, Gambina G, He Y, Rapatz G, Nagel J, Lane R: Rivastigmine and donepezil treatment in moderate to moderately-severe Alzheimer's disease over a 2-year period. Curr Med Res Opin 2005, 21:1317-1327.

57. Wilkinson DG, Passmore AP, Bullock R, Hopker SW, Smith R, Potocnik FC, Maud CM, Engelbrecht I, Hock C, leni JR, Bahra RS: A multinational, randomised, 12-week, comparative study of donepezil and rivastigmine in patients with mild to moderate Alzheimer's disease. Int J Clin Pract 2002, 56:441-446.

58. Jones RW, Soininen $H$, Hager $K$, Aarsland D, Passmore P, Murthy A, Zhang R, Bahra R: A multinational, randomised, 12-week study comparing the effects of donepezil and galantamine in patients with mild to moderate Alzheimer's disease. Int J Geriatr Psychiatry 2004, 19:58-67.

59. Wilcock G, Howe I, Coles H, Lilienfeld S, Truyen L, Zhu Y, Bullock R, Kershaw P: A long-term comparison of galantamine and donepezil in the treatment of Alzheimer's disease. Drugs Aging 2003, 20:777-789.

60. Hogan DB, Goldlist B, Naglie G, Patterson C: Comparison studies of cholinesterase inhibitors for Alzheimer's disease. Lancet Neurol 2004, 3:622-626.

61. Tariot PN, Farlow MR, Grossberg GT, Graham SM, McDonald S, Gergel I: Memantine treatment in patients with moderate to severe Alzheimer disease already receiving donepezil: a randomized controlled trial. JAMA 2004, 291:317-324.

62. Porsteinsson AP, Grossberg GT, Mintzer J, Olin JT: Memantine treatment in patients with mild to moderate Alzheimer's disease already receiving a cholinesterase inhibitor: a randomized, double-blind, placebo-controlled trial. Curr Alzheimer Res 2008, 5:83-89.

63. Hogan DB, Bailey P, Carswell A, Clarke B, Cohen C, Forbes D, Man-Son-Hing M, Lanctôt K, Morgan D, Thorpe L: Management of mild to moderate Alzheimer's disease and dementia. Alzheimers Dement 2007, 3:355-384.

64. Reisberg B, Ferris SH, de Leon MJ, Crook T: The Global Deterioration Scale for assessment of primary degenerative dementia. Am J Psychiatry 1982,
139:1136-1139.

65. Amuah JE, Hogan DB, Eliasziw M, Supina A, Beck P, Downey W, Maxwell CJ: Persistence with cholinesterase inhibitor therapy in a population-based cohort of patients with Alzheimer's disease. Pharmacoepidemiol Drug Saf 19:670-679.

66. Naranjo CA, Busto U, Sellers EM, Sandor P, Ruiz I, Roberts EA, Janecek E, Domecq C, Greenblatt DJ: A method for estimating the probability of adverse drug reactions. Clin Pharmacol Ther 1981, 30:239-245.

67. Herrmann N, Black SE, Li A, Lanctôt KL: Discontinuing cholinesterase inhibitors: results of a survey of Canadian dementia experts. Int Psychogeriatr 2011, 23:539-545.

68. Scarpini E, Bruno G, Zappala G, Adami M, Richarz U, Gaudig M, Jacobs A Schauble B: Cessation versus continuation of galantamine treatment after 12 months of therapy in patients with Alzheimer's disease: a randomized double blind, placebo controlled withdrawal trial. J Alzheimers Dis 2011 , 26:211-220

69. Singh S, Dudley C: Discontinuation syndrome following donepezil cessation. Int J Geriatr Psychiatry 2003, 18:282-284.

70. Doody RS, Geldmacher DS, Gordon B, Perdomo CA, Pratt RD: Open-label, multicenter, phase 3 extension study of the safety and efficacy of donepezil in patients with Alzheimer disease. Arch Neurol 2001, 58:427-433

71. Thompson S, Herrmann N, Rapoport MJ, Lanctôt KL: Efficacy and safety of antidepressants for treatment of depression in Alzheimer's disease: a metaanalysis. Can J Psychiatry 2007, 52:248-255.

72. Olin JT, Schneider LS, Katz IR, Meyers BS, Alexopoulos GS, Breitner JC, Bruce ML, Caine ED, Cummings JL, Devanand DP, Krishnan KR, Lyketsos CG, Lyness JM, Rabins PV, Reynolds CF, 3rd, Rovner BW, Steffens DC, Tariot PN, Lebowitz $\mathrm{BD}$ : Provisional diagnostic criteria for depression of Alzheimer disease. Am J Geriatr Psychiatry 2002, 10:125-128.

73. Rosenberg PB, Drye LT, Martin BK, Frangakis C, Mintzer JE, Weintraub D, Porsteinsson AP, Schneider LS, Rabins PV, Munro CA, Meinert CL, Lyketsos CG: Sertraline for the treatment of depression in Alzheimer disease. Am J Geriatr Psychiatry 18:136-145.

74. Banerjee S, Hellier J, Dewey M, Romeo R, Ballard C, Baldwin R, Bentham P, Fox C, Holmes C, Katona C, Knapp M, Lawton C, Lindesay J, Livingston G, McCrae N, Moniz-Cook E, Murray J, Nurock S, Orrell M, O'Brien J, Poppe M, Thomas A, Walwyn R, Wilson K, Burns A: Sertraline or mirtazapine for depression in dementia (HTA-SADD): a randomised, multicentre, double-blind, placebocontrolled trial. Lancet 378:403-411.

75. Eustace A, Coen R, Walsh C, Cunningham CJ, Walsh JB, Coakley D, Lawlor BA A longitudinal evaluation of behavioural and psychological symptoms of probable Alzheimer's disease. Int J Geriatr Psychiatry 2002, 17:968-973.

76. Olin JT, Katz IR, Meyers BS, Schneider LS, Lebowitz BD: Provisional diagnostic criteria for depression of Alzheimer disease: rationale and background. Am J Geriatr Psychiatry 2002, 10:129-141.

77. Herrmann N, Gauthier S, Lysy PG: Clinical practice guidelines for severe Alzheimer's disease. Alzheimers Dement 2007, 3:385-397.

78. Herrmann N, Lanctôt KL: Pharmacologic management of neuropsychiatric symptoms of Alzheimer disease. Can J Psychiatry 2007, 52:630-646.

79. Tariot PN, Schneider LS, Cummings J, Thomas RG, Raman R, Jakimovich $L$, Loy R, Bartocci B, Fleisher A, Ismail MS, Porsteinsson A, Weiner M, Jack CR, Jr.. Thal L, Aisen PS: Chronic divalproex sodium to attenuate agitation and clinical progression of Alzheimer disease. Arch Gen Psychiatry 2011, 68:853-861.

80. Fleisher AS, Truran D, Mai JT, Langbaum JB, Aisen PS, Cummings JL, Jack CR, $J r$, Weiner MW, Thomas RG, Schneider LS, Tariot PN: Chronic divalproex sodium use and brain atrophy in Alzheimer disease. Neurology 2011, 77:1263-1271.

81. Kales HC, Zivin K, Kim HM, Valenstein M, Chiang C, Ignacio RV, Ganoczy D, Cunningham F, Schneider LS, Blow FC: Trends in antipsychotic use in dementia 1999-2007. Arch Gen Psychiatry 2011, 68:190-197.

82. Holmes C, Wilkinson D, Dean C, Vethanayagam S, Olivieri S, Langley A Pandita-Gunawardena ND, Hogg F, Clare C, Damms J: The efficacy of donepezil in the treatment of neuropsychiatric symptoms in Alzheimer disease. Neurology 2004, 63:214-219.

83. Howard RJ, Juszczak E, Ballard CG, Bentham P, Brown RG, Bullock R, Burns AS, Holmes C, Jacoby R, Johnson T, Knapp M, Lindesay J, O'Brien JT, Wilcock G, Katona C, Jones RW, DeCesare J, Rodger M: Donepezil for the treatment of agitation in Alzheimer's disease. N Engl J Med 2007, 357:1382-1392.

84. Gauthier S, Herrmann N: A randomized controlled trial of memantine treatment in a behaviorally enriched sample of patients with moderate to 
severe Alzheimer's Disease [abstract]. In The 6th Canadian Conference on Dementia (CCD); October 27-292011; Montreal, QC.

85. De Deyn P, Jeste DV, Swanink R, Kostic D, Breder C, Carson WH, Iwamoto T Aripiprazole for the treatment of psychosis in patients with Alzheimer's disease: a randomized, placebo-controlled study. J Clin Psychopharmacol 2005, 25:463-467.

86. Mintzer JE, Tune LE, Breder CD, Swanink R, Marcus RN, McQuade RD, Forbes A: Aripiprazole for the treatment of psychoses in institutionalized patients with Alzheimer dementia: a multicenter, randomized, double-blind, placebo-controlled assessment of three fixed doses. Am J Geriatr Psychiatry 2007, 15:918-931.

87. Streim JE, Porsteinsson AP, Breder CD, Swanink R, Marcus R, McQuade R, Carson WH: A randomized, double-blind, placebo-controlled study of aripiprazole for the treatment of psychosis in nursing home patients with Alzheimer disease. Am J Geriatr Psychiatry 2008, 16:537-550.

88. Maher AR, Maglione M, Bagley S, Suttorp M, Hu JH, Ewing B, Wang Z, Timmer M, Sultzer D, Shekelle PG: Efficacy and comparative effectiveness of atypical antipsychotic medications for off-label uses in adults: a systematic review and meta-analysis. JAMA 2011, 306:1359-1369.

89. Vigen CL, Mack WJ, Keefe RS, Sano M, Sultzer DL, Stroup TS, Dagerman KS, Hsiao JK, Lebowitz BD, Lyketsos CG, Tariot PN, Zheng L, Schneider LS: Cognitive effects of atypical antipsychotic medications in patients with Alzheimer's disease: outcomes from CATIE-AD. Am J Psychiatry 2011 168:831-839.

90. Lipscombe LL, Levesque L, Gruneir A, Fischer HD, Juurlink DN, Gill SS, Herrmann N, Hux JE, Anderson GM, Rochon PA: Antipsychotic drugs and hyperglycemia in older patients with diabetes. Arch Intern Med 2009, 169:1282-1289.

91. Zheng L, Mack WJ, Dagerman KS, Hsiao JK, Lebowitz BD, Lyketsos CG, Stroup TS, Sultzer DL, Tariot PN, Vigen C, Schneider LS: Metabolic changes associated with second-generation antipsychotic use in Alzheimer's disease patients: the CATIE-AD study. Am J Psychiatry 2009, 166:583-590.

92. Rochon PA, Stukel TA, Sykora K, Gill S, Garfinkel S, Anderson GM, Normand SL, Mamdani M, Lee PE, Li P, Bronskill SE, Marras C, Gurwitz JH: Atypical antipsychotics and parkinsonism. Arch Intern Med 2005, 165:1882-1888.

93. Ballard C, Hanney ML, Theodoulou M, Douglas S, McShane R, Kossakowski K Gill R, Juszczak E, Yu LM, Jacoby R: The dementia antipsychotic withdrawal trial (DART-AD): long-term follow-up of a randomised placebo-controlled trial. Lancet Neurol 2009, 8:151-157.

94. Huybrechts KF, Gerhard T, Crystal S, Olfson M, Avorn J, Levin R, Lucas JA, Schneeweiss S: Differential risk of death in older residents in nursing homes prescribed specific antipsychotic drugs: population based cohort study. BMJ 2012, 344:e977.

95. Huybrechts KF, Rothman KJ, Silliman RA, Brookhart MA, Schneeweiss S: Risk of death and hospital admission for major medical events after initiation of psychotropic medications in older adults admitted to nursing homes. CMAJ 2011, 183:E411-E419.

96. Kales HC, Kim HM, Zivin K, Valenstein M, Seyfried LS, Chiang C, Cunningham F, Schneider LS, Blow FC: Risk of mortality among individual antipsychotics in patients with dementia. Am J Psychiatry 2012, 169:71-79.

97. Pollock BG, Mulsant BH, Rosen J, Mazumdar S, Blakesley RE, Houck PR, Huber KA: A double-blind comparison of citalopram and risperidone for the treatment of behavioral and psychotic symptoms associated with dementia. Am J Geriatr Psychiatry 2007, 15:942-952.

98. Barak Y, Plopski I, Tadger S, Paleacu D: Escitalopram versus risperidone for the treatment of behavioral and psychotic symptoms associated with Alzheimer's disease: a randomized double-blind pilot study. Int Psychogeriatr 2011. [Epub ahead of print]

99. Bergh S, Selbaek G, Engedal K: Discontinuation of antidepressants in people with dementia and neuropsychiatric symptoms (DESEP study): double blind, randomised, parallel group, placebo controlled trial. BMJ 2012, 344:e1566

100. Seitz DP, Adunuri N, Gill SS, Gruneir A, Herrmann N, Rochon P: Antidepressants for agitation and psychosis in dementia. Cochrane Database Syst Rev 2011, 2:CD008191.

101. Fernandez HH, Trieschmann ME, Friedman JH: Treatment of psychosis in Parkinson's disease: safety considerations. Drug Saf 2003, 26:643-659.

102. Schneider LS, Dagerman K, Insel PS: Efficacy and adverse effects of atypical antipsychotics for dementia: meta-analysis of randomized, placebocontrolled trials. Am J Geriatr Psychiatry 2006, 14:191-210.
103. Cheung G, Stapelberg J: Quetiapine for the treatment of behavioural and psychological symptoms of dementia (BPSD): a meta-analysis of randomised placebo-controlled trials. NZMed J 2011, 124:39-50

104. Seppi K, Weintraub D, Coelho M, Perez-Lloret S, Fox SH, Katzenschlager R, Hametner EM, Poewe W, Rascol O, Goetz CG, Sampaio C: The Movement Disorder Society Evidence-Based Medicine Review Update: treatments for the non-motor symptoms of Parkinson's disease. Mov Disord 2011, 26(Suppl 3):S42-S80.

105. Piguet O, Hornberger M, Mioshi E, Hodges JR: Behavioural-variant frontotemporal dementia: diagnosis, clinical staging, and management. Lancet Neurol 10:162-172.

106. Lampl Y, Sadeh M, Lorberboym M: Efficacy of acetylcholinesterase inhibitors in frontotemporal dementia. Ann Pharmacother 2004, 38:1967-1968

107. Diehl-Schmid J, Forstl H, Perneczky R, Pohl C, Kurz A: A 6-month, open-label study of memantine in patients with frontotemporal dementia. Int J Geriatr Psychiatry 2008, 23:754-759.

108. Moretti R, Torre P, Antonello RM, Cattaruzza T, Cazzato G, Bava A: Rivastigmine in frontotemporal dementia: an open-label study. Drugs Aging 2004 21:931-937.

109. Boxer AL, Lipton AM, Womack K, Merrilees J, Neuhaus J, Pavlic D, Gandhi A, Red D, Martin-Cook K, Svetlik D, Miller BL: An open-label study of memantine treatment in 3 subtypes of frontotemporal lobar degeneration. Alzheimer Dis Assoc Disord 2009, 23:211-217.

110. Kertesz A, Morlog D, Light M, Blair M, Davidson W, Jesso S, Brashear R: Galantamine in frontotemporal dementia and primary progressive aphasia. Dement Geriatr Cogn Disord 2008, 25:178-185.

111. Vercelletto M, Boutoleau-Bretonniere C, Volteau C, Puel M, Auriacombe S, Sarazin M, Michel BF, Couratier P, Thomas-Anterion C, Verpillat P, Gabelle A, Golfier V, Cerato E, Lacomblez L: Memantine in behavioral variant frontotemporal dementia: negative results. J Alzheimers Dis 2011, 23:749-759.

112. Swartz JR, Miller BL, Lesser IM, Darby AL: Frontotemporal dementia: treatment response to serotonin selective reuptake inhibitors. J Clin Psychiatry 1997, 58:212-216.

113. Huey ED, Garcia C, Wassermann EM, Tierney MC, Grafman J: Stimulant treatment of frontotemporal dementia in 8 patients. J Clin Psychiatry 2008, 69:1981-1982.

114. Herrmann N, Black SE, Chow T, Cappell J, Tang-Wai DF, Lanctot KL: Serotonergic function and treatment of behavioral and psychological symptoms of frontotemporal dementia. Am J Geriatr Psychiatry 2012, 20:789-797.

115. Lebert F, Stekke W, Hasenbroekx C, Pasquier F: Frontotemporal dementia: a randomised, controlled trial with trazodone. Dement Geriatr Cogn Disord 2004, 17:355-359.

116. Moretti R, Torre P, Antonello RM, Cazzato G, Bava A: Frontotemporal dementia: paroxetine as a possible treatment of behavior symptoms. A randomized, controlled, open 14-month study. Eur Neurol 2003, 49:13-19.

117. Deakin JB, Rahman S, Nestor PJ, Hodges JR, Sahakian BJ: Paroxetine does not improve symptoms and impairs cognition in frontotemporal dementia: a double-blind randomized controlled trial. Psychopharmacology (Berl) 2004, 172:400-408.

118. Sadowsky CH, Farlow MR, Meng X, Olin JT: Safety and tolerability of rivastigmine transdermal patch compared with rivastigmine capsules in patients switched from donepezil: data from three clinical trials. Int J Clin Pract 2010, 64:188-193.

119. Schwartz LM, Woloshin S: How the FDA forgot the evidence: the case of donepezil $23 \mathrm{mg}$. BMJ 2012, 344:e1086.

120. Herrmann N, Chau SA, Kircanski I, Lanctôt KL: Current and emerging drug treatment options for Alzheimer's disease: a systematic review. Drugs 2011, 71:2031-2065

\section{doi:10.1186/alzrt201}

Cite this article as: Herrmann N, et al.: Pharmacological recommendations for the symptomatic treatment of dementia: the Canadian Consensus Conference on the Diagnosis and Treatment of Dementia 2012. Alzheimer's Research \& Therapy 2013, 5(Suppl 1):S5. 